\title{
PERANCANGAN HUG MACHINE WRAP UNTUK ALAT TERAPI AUTISME
}

\author{
*Sumar Hadi Suryo, Awan Raswan, Jamari, Ismoyo Haryanto \\ Magister Teknik Mesin, Fakultas Teknik, Universitas Diponegoro \\ Jl. Prof. Soedarto SH, Tembalang, Semarang 50272 Indonesia \\ *E-mail: autismemtmundip@gmail.com
}

\begin{abstract}
Today children born with the syndrome of autism is increasing. People with autism have a greater sensitivity to stimulation motor. This will cause them to feel discomfort when making physical contact with another person. Autism therapy can use the device as a media aide. Media autism therapies to be developed is the hug machine wrap. This media uses the principle of doing deep pressure therapy.

At the hug machine made from fabric following the body shape of the user. The fabric binding of the user's body from shoulders to toes. Ballon added as a producer of pressure. Balloon filled with air pressure and the pressure can be regulated.

Hug machine wrap designed to create deep pressure by inflating a balloon on inside, fabric pattern design that can cover the shoulder down to the legs will give equal emphasis. Therapeutic application of deep pressure on children with autism are expected to assist in receiving physical contact to the social environment and increase peace of children with autism.
\end{abstract}

Keywords: autism therapy, deep pressure, design, inflating wrap

\section{PENDAHULUAN}

Perbandingan kelahiran antara anak normal dengan anak yang menderita Autism atau Autism Spectrum Desorders (ASD) kian terpaut tipis. Dalam dua dekade terakhir ini, penyandang Autism dan Autism Spectrum Desorder (ASD) di seluruh dunia meningkat sangat drastis. Setiap satu dekade terjadi peningkatan 10 kali lipat. Pada tahun 1990 didapat 4 anak austik dari 10.000 kelahiran $(1: 2.500)$, sedangkan pada saat ini meningkat menjadi 1 : 100, artinya ada peningkatan sebesar 25 kali lipat (CDC 2001), kemudian penelitian terakhir menyebutkan peningkatan ke arah yang lebih tinggi perbandingannya yaitu sekitar 1:88[1].

Pada anak penderita Autism memiliki sensifitas yang lebih terhadap stimulasi motorik. Hal ini akan berakibat anak akan merasakan ketidak nyamanan ketika melakukan kontak fisik dengan orang lain, ketidak nyaman ini biasanya berupa penolakan secara langsung. Sebagai contoh ketika anak dipeluk oleh orang tuanya akan meronta-ronta. Begitu pula jika anak merasa tidak nyaman dikarenakan lingkungan, anak akan memberikan penolakan berupa rasa marah, melempar benda-benda yang ada disekitarnya. Rasa tidak nyaman ini tentu akan berakibat buruk bagi perkembangan anak, bahkan dapat mengancam jiwa anak. Hal ini dapat ditanggulangi dengan cara melakukan terapi terhadap anak dengan Autism secara baik dan berkelanjutan.

\subsection{Perkembangan Terapi Deep Pressure}

Sebuah penelitian yang dilakukan oleh Temple Grandin pada tahun 1965 dihasilkan alat terapi untuk menghilangkan ketegangan (stress relieving device) atau lebih dikenal sebagai mesin pemeluk (hug machine). Prinsip dari alat ini adalah memberikan simulasi pelukan atau pemberian tekanan ke tubuh anak untuk menciptakan deep pressure yang dapat memberikan efek ketenangan [2].

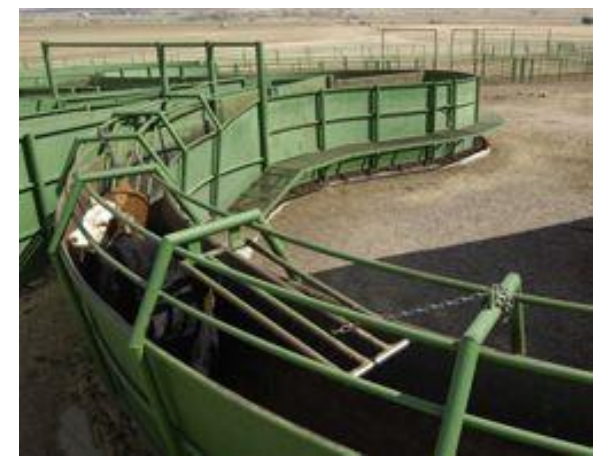

Gambar 1. Kekang sapi desain Temple Grandin [4]. 
Temple Grandin juga seorang yang sejak kecil mengidap Autism. Alat ini ditemukan oleh Temple Grandin melihat dari cara peternak memerah susu sapi atau melakukan insemenasi buatan terhadap sapi dengan memasukkan sapi ke dalam alat pengekang. Sapi yang dimasukkan dalam alat pengekang menjadi tenang ketika susunya diperah ataupun dilakukan insemenasi. Kemudian muncul ide Temple Grandin untuk mengaplikasikan alat ini kepada dirinya dengan melakukan beberapa perubahan pada alat kekang sapi tersebut. Pada awalnya alat ini ditentang oleh para ahli karena dianggap tidak manusiawi. Tetapi kemudian dengan berbagai penelitian yang dilakukan mneyimpulkan bahwa alat ini ternyata dapat bermanfaaat dalam terapi Autism. Dengan alat ini penderita Autism dapat menerima kontak fisik dari lingkungan sosialnya, kemudian gejala Autism lain juga dapat ditekan.

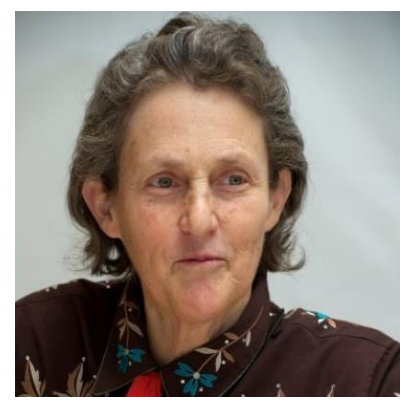

Gambar 2. Temple Grandin, Ph.D [3].

Alat ini berbentuk persegi dengan papan penjepit berbentuk V. Alat ini menggunakan silinder pneumatik sebagai penarik dari papan penekan. Pada papan penekannya dilapisi dengan menggunakan busa yang terdapat pada sisi dalam papan penekannya. Penggguna menggunakan alat ini dengan cara merunduk. Kemudian tangan dari pengguna dapat mengoperasikan dengan menarik tuas untuk membangkitkan tekanan dalam sistem pneumatik yang kemudian menarik papan penekan.

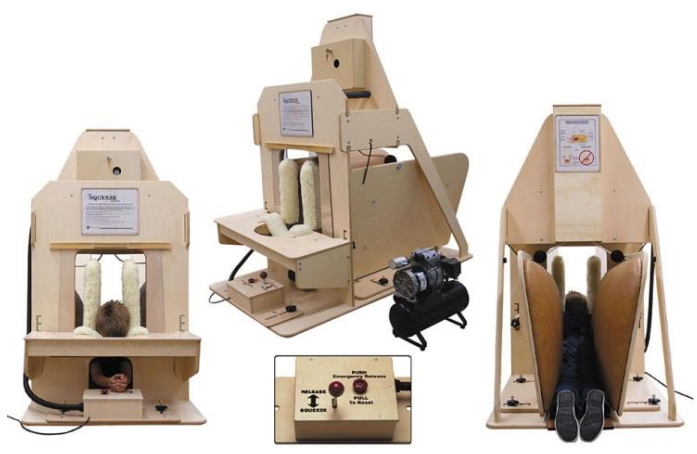

Gambar 3. Squeezemachine produksi therafin corp [6].

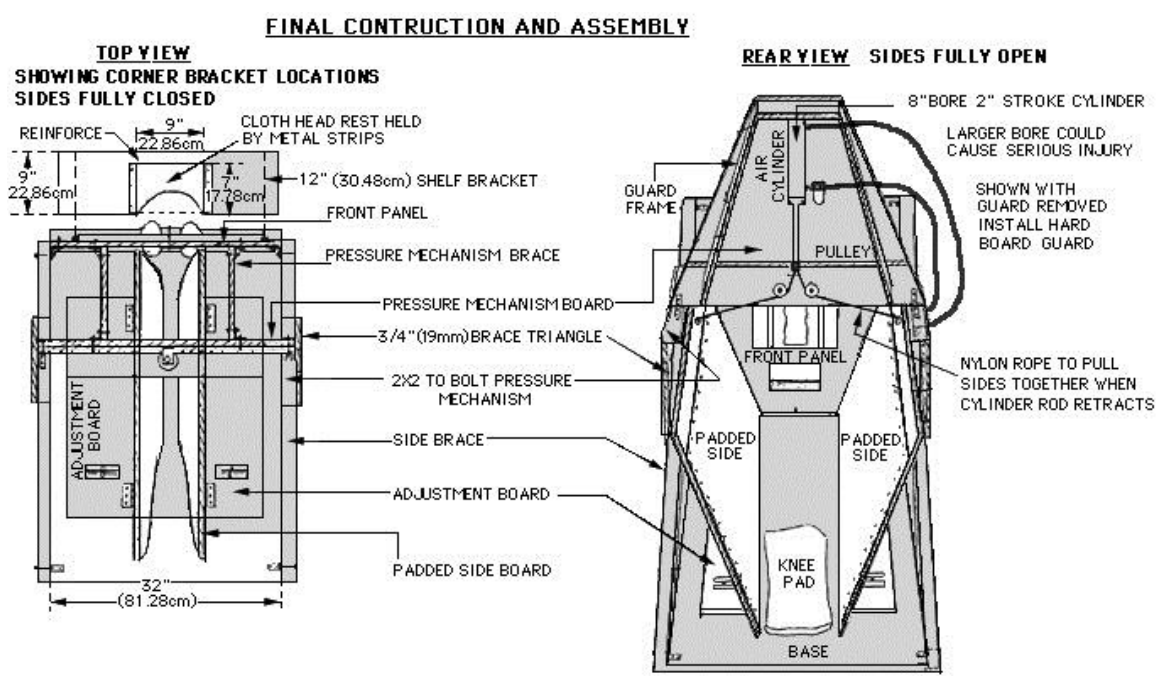

Gambar 4. Desain Hug Machine [5]. 


\section{METODOLOGI}

Metode penelitian yang dilakukan pada perancangan hug machine inflating wrap adalah metode eksperimen (experimen researched method), dengan tahapan sebagai berikut:

\subsection{Studi Lapangan}

Studi lapangan ke Yayasan Nathanisa "AGCA CENTER" Surabaya, sebagai pusat terapi penyandang autisme yang beralamat di Jalan Ngagel Jaya Tengah III/21, Surabaya. Dimana yayasan ini bergerak dalam bidang terapi anak berkebutuhan khusus salah satunya anak dengan Autism. Data awal tentang kebutuhan dari tempat terapi akan diperoleh. Serta tentang tata cara penanganan dari anak dengan Autism.

\subsection{Studi Pustaka}

Studi literatur dengan mempelajari jurnal-jurnal internasional dan buku-buku yang berkaitan dengan alat hug machine. Kemudian pengambilan data tambahan akan dilakukan observasi terapi di Yayasan Nathanasia "AGCA CENTER Cabang Semarang", Jalan Badak V Timur No. 50. Diharapkan dapat membantu menambah perbendaharaan pustaka penanganan terapi anak Autism.

\subsection{Perancangan}

Pada perancangan hug machine inflating wrap melalui beberapa tahapan antara lain:

\subsubsection{Desain Gambar}

Alat akan didesain menggunakan software Catia, dengan penggunaan software ini perancangan alat dapat dilakukan secara detail dan dapat ditampilkan secara 3 dimensi. Sehingga mempermudah dalam proses selanjutnya. Dalam desain gambar ini akan dimasukkan parameter yang telah dilakukan studi sebelumnya. Mulai dari proporsi badan dari anak, kebiasaan anak serta faktor keamananan yang telah diperhitungkan sebelumnya. Demikian pula didesain mengenai sistem udara yang terintegrasi dengan alat. Dimana sistem ini yang akan membuat penekanan udara terhadap penggunanya.

\subsubsection{Pemilihan Bahan}

Pemilihan bahan dilakukan untuk membantu dalam pembangkitan deep pressure pada penggunanya. Tentunya bahan yang digunakan harus aman terhadap kulit, nyaman serta mudah dalam perawatannya. Juga diperhitungkan kemudahan dalam proses pemasangannya.

\section{HASIL dan PEMBAHASAN}

Pada perancangan alat hug machine inflating wrap akan menghasilkan beberapa dokumen, antara lain:

\subsection{Gambar Perancangan}

Alat pemeluk hug machine inflating wrap dirancang menggunakan bantuan software komputer, dengan bantuan software ini dapat disimulasikan bentuk akhir dari hug machine inflating wrap.

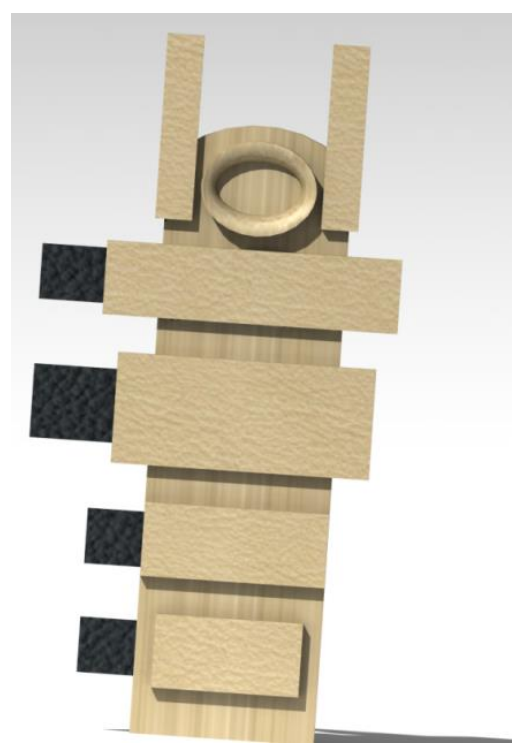

Gambar 5. Desain 3 dimensi hug machine inflating wrap. 


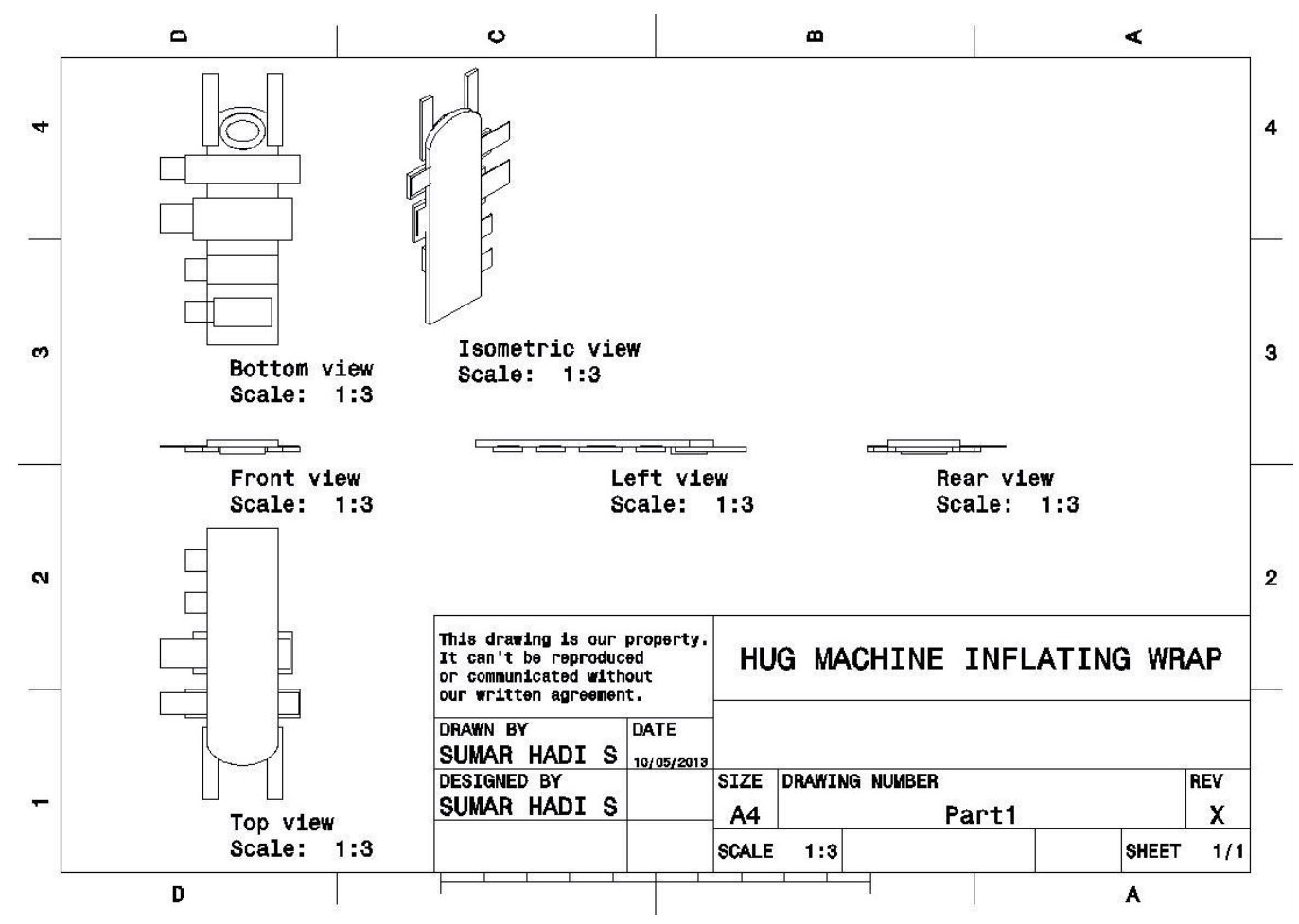

Gambar 6. Gambar teknik hug machine inflating wrap.

\subsection{Skema Penekan Udara Hug Machine Inflating Wrap.}

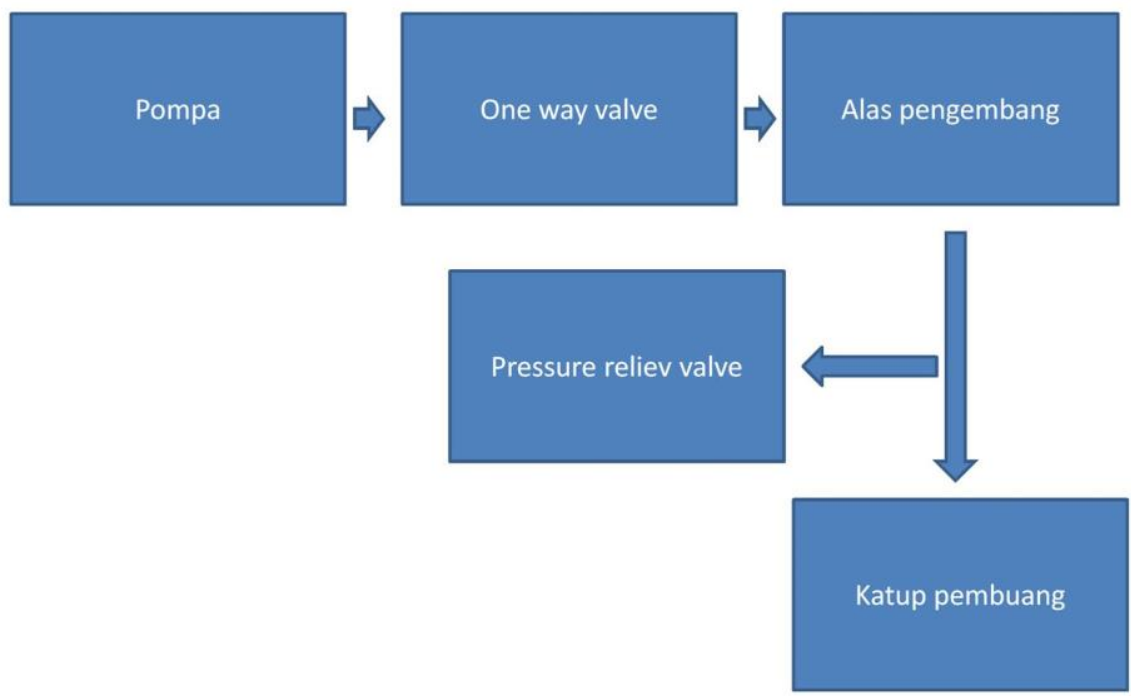

Gambar 7. Skema saluran udara hug machine inflating wrap.

Pada sistem saluran udara yang berfungsi sebagai penekan balon udara yang terletak pada lengan pemeluk menggunakan sistem sederhana yang bertujuan untuk meringkas dari besar alat. Pada hug machine inflating wrap dibatasi sekitar 25-30 psi dengan menggunakan Pressure Relief Valve.

\subsection{Pemilihan Bahan}

Bahan yang akan digunakan dalam hug machine inflating wrap terdiri dari berbagai macam bahan kain. Pada bagian dalam berupa busa yang dibentuk memanjang dengan berbagai lapisan, lapisan tersebut antara lain adalah: 


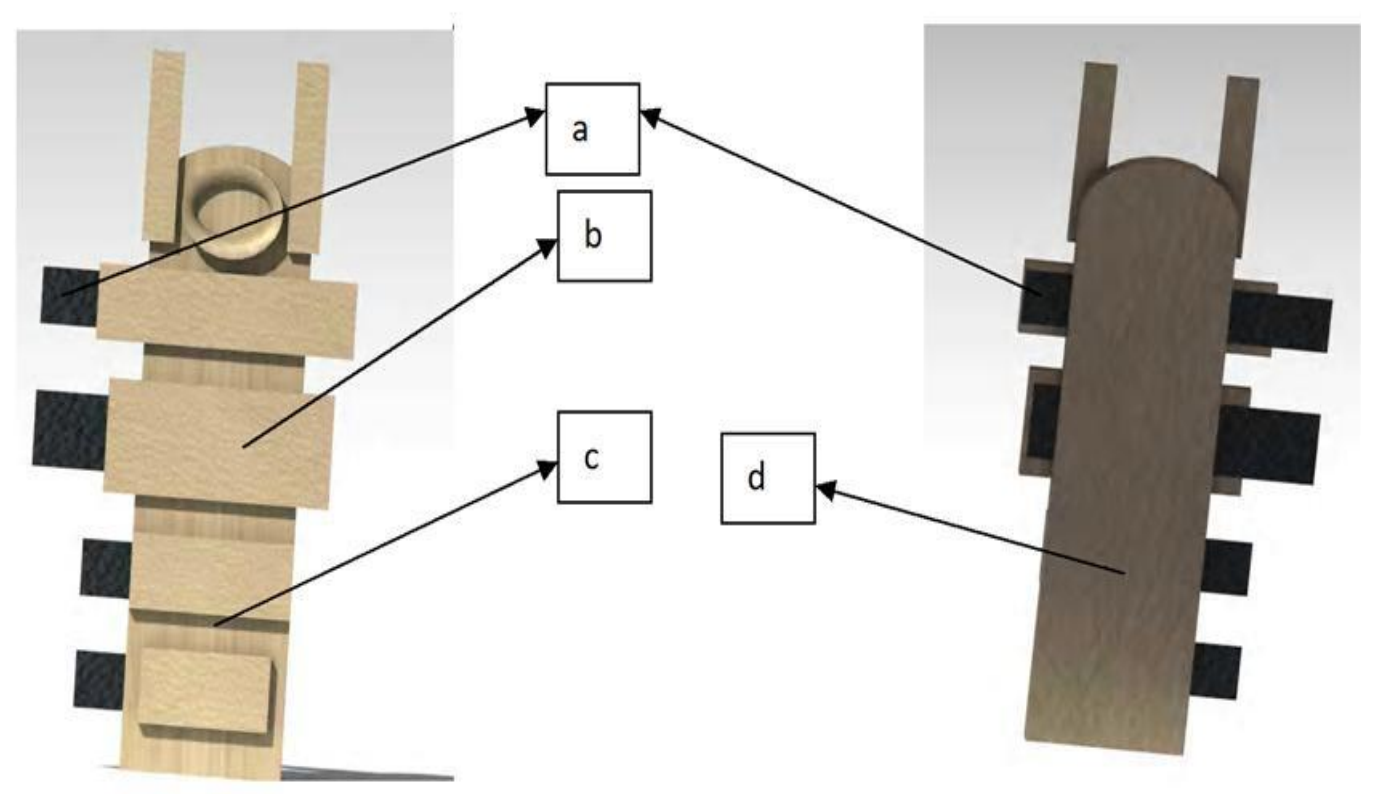

Gambar 8. Jenis bahan hug machine inflating wrap.

Tabel 1. Lapisan bahan hug machine inflating wrap.

\begin{tabular}{cl}
\hline Bagian & \multicolumn{1}{c}{ Bahan } \\
\hline $\mathrm{a}$ & Kain velkro \\
\hline $\mathrm{b}$ & Kain Dril berlapis kain perlak \\
\hline $\mathrm{c}$ & Kain katun \\
\hline $\mathrm{d}$ & Kain katun \\
\hline
\end{tabular}

Pada bagian (a) diaplikasikan kain velkro sebagai perekat yang berfungsi sebagai pengikat ketika alat digunakan, kemudian pada bagian (b) merupakan kain dril berlapis kain perlak yang membungkus dari balon udara yang berfungsi sebagai penekan. Kemudian bagian (c) dan bagian (d) merupakan kain katun yang ditujukan sebagai penyerap keringat ketika digunakan.

\section{KESIMPULAN}

Hug machine inflating wrap disusun dari busa yang dibungkus menggunakan kain dengan bentuk memanjang mengikuti bentuk tubuh, kemudian terdapat pengikat dari bahan yang sama yang berguna untuk mengikat tubuh. Pengikat tubuh ini juga berfungsi sebagai pemberi tekanan pada pengguna. Penyetelan dari ukuran tubuh pengguna menggunakan kain perekat yang terdapat pada pengikat tubuh.

Pada hug machine inflating wrap ikatan pada tubuh didesain lebih menjangkau semua area tubuh sehingga akan lebih menimbulkan efek deep pressure yang merata. Kemudian pada pengikat tubuh akan ditambahkan balon sebagai pencipta tekanan. Balon ini dapat mengembang sesuai dengan keinginan pengguna. Tetapi tekanan yang dihasilkan dibatasi agar tidak menyakiti dari pengguna.

Hug machine inflating wrap diharapkan mampu mengisi kekosongan alat terapi yang digunakan dalam terapi di rumah ataupun di sekolah khusus. Dengan menggunakan hug machine inflating wrap anak penderita autism dapat mencapai ketenangan serta mencapai kesembuhan ketika menggunakan alat ini.

\section{REFERENSI}

[1] CDC-Autism Spectrum Disorder (ASDs)-NCBDDD www.cdc.gov/ncbddd/autism/index.html Diakses: 4/8/2013 9:19 PM

[2] Grandin, Temple, Ph.D. (1992). Calming Effects of Deep Touch Pressure in Patients with Autistic Disorder, College Students, and Animals, Journal of Child and Adolescent Psychopharmacology, Volume 2, Number 1, Mary Ann Liebert, Inc., Publishers.

[3] http:// biography.com (diakses 15 Oktober 2012, jam 15.30).

[4] http://www.colostate.edu/features/temple-grandin.aspx (diakses 7 mei 2013, jam 17.30).

[5] http://www.grandin.com/inc/squeeze-10.html (diakses 15 Oktober 2012, jam 15.30).

[6] http://www.therafin.com/squeezemachine.htm (diakses 7 mei 2013, jam 17.30). 